\title{
A interdisciplinaridade em Direito tributário: as normas de impacto tributário contidas em diplomas atinentes a outros ramos do direito
}

https://doi.org/10.21814/uminho.ed.30.30

Tânia Meireles da Cunha

Juíza Desembargadora no Tribunal Central Administrativo Sul

\section{0 direito tributário e a sua interligação com os demais ramos do direito}

Se comummente o direito tributário é visto como uma disciplina algo hermética, a realidade demonstra-nos que tal visão não corresponde à realidade, sendo, no seu âmbito, inúmeras vezes convocados regimes de outros ramos do direito.

Essa interdisciplinaridade surge, desde logo, refletida no . $^{\circ} 2$ do art. ${ }^{\circ} 11 .^{\circ}$ da Lei Geral Tributária (LGT), atinente à interpretação de normas fiscais, no qual se refere que "[s]empre que, nas normas fiscais, se empreguem termos próprios de outros ramos de direito, devem os mesmos ser interpretados no mesmo sentido daquele que aí têm, salvo se outro decorrer diretamente da lei".

Desde o direito administrativo ao direito da família, desde o direito das obrigações aos direitos reais, desde o direito societário ao direito da insolvência, não há praticamente ramo do direito que, em algum momento, não se cruze com o direito tributário, implicando que muitas das decisões proferidas tenham de ter sempre em consideração esta interdisciplinaridade.

Convocando-se, pois, disciplinas jurídicas tão diversificadas, uma tarefa que cabe ao julgador passa, naturalmente, pela interpretação e conformação de determinados institutos, tarefa hermenêutica nem sempre destituída de dificuldades.

Esta questão, por outro lado e inevitavelmente, abrange os casos de existência de normas, passíveis de serem consideradas normas tributárias, em diplomas legislativos criados e pensados para outras disciplinas do direito.

A situação acarreta dificuldades acrescidas atentas as exigências constantes da Constituição da República Portuguesa (CRP), concretamente as atinentes à reserva de lei parlamentar, prevista no seu $\operatorname{art.}^{\circ} 165 .^{\circ},{ }^{\circ}{ }^{\circ} 1$, al. i), que nem sempre são tidas 
em conta pelo legislador, estamos em crer que pelo facto de tais normas estarem contidas em diplomas não especificamente orientados para o direito fiscal.

Propomo-nos, neste seguimento, fazer uma abordagem de duas normas onde justamente tal questão se colocou.

\section{A reserva de lei parlamentar e o princípio da legalidade em matéria de impostos}

Antes de passarmos à análise de dois casos específicos onde a questão da inconstitucionalidade orgânica se colocou, cumpre, ainda que muito sumariamente, circunscrever o alcance do princípio da legalidade em matéria de impostos.

Não obstante o nosso ordenamento configurar de forma tripartida os tributos - impostos, taxas e demais contribuições financeiras a favor das entidades públicas apenas nos iremos debruçar sobre os primeiros, dado que são tributos em relação aos quais a reserva de lei parlamentar tem um alcance mais alargado.

Assim, quanto à noção de imposto, este pode ser definido como uma prestação pecuniária unilateral, imposta coativa ou autoritariamente pelo Estado ou por uma entidade pública, sem caráter sancionatório, visando angariar receita ou a prossecução de outras finalidades públicas ${ }^{1}$. É ainda de considerar que, do art. ${ }^{\circ} 103 .{ }^{\circ}$, n. $^{\circ} 1$, da CRP, resulta igualmente que o sistema fiscal visa diminuir as desigualdades e promover a distribuição de rendimentos e riquezas, conjugando o que se poderá denominar como um interesse financeiro ou imediato com um interesse de justiça social, mediato ou metajurídico.

A tributação, designadamente por via de impostos, é, pois, regida por um conjunto de princípios, com assento na nossa lei fundamental, que podem, desde logo, dividir-se entre princípios que definem limites de natureza formal e os que definem limites de natureza material².

Do ponto de vista dos limites de natureza formal, surge-nos o princípio da legalidade fiscal, na perspetiva da reserva (relativa) de lei parlamentar, espelhando o paradigma do no taxation without representation.

Assim, o já mencionado art. $165 .^{\circ}$, n..$^{\circ}$ 1, al. i), da CRP, prevê que seja da competência relativa da Assembleia da República (AR) legislar em matéria de impostos e sistema fiscal e sobre o regime geral das taxas e contribuições financeiras.

Portanto, no que toca aos impostos, a reserva relativa de lei abrange tudo o que respeite à sua criação, determinação da incidência (nas suas diversas vertentes - objetiva,

1 Cfr. NABAIS, José Casalta - Direito Fiscal. 5. ${ }^{a}$ Ed. Coimbra: Almedina, 2009, pp. 18 e 19, VASQUES, Sérgio - Manual de Direito Fiscal. Coimbra: Almedina, 2014, pp. 186 e 187, e DOURADO, Ana Paula - Direito Fiscal - Lições. Coimbra: Almedina, 2015, pp. 38 a 44.

2 Cfr. NABAIS, José Casalta, ob. cit., pp. 134 a 162 
subjetiva, temporal e territorial) ${ }^{3}$, da taxa, dos benefícios fiscais e das garantias dos contribuintes, em consonância com o que resulta do n. ${ }^{\circ} 2$ do art. ${ }^{\circ} 103 .{ }^{\circ}$ da CRP.

O princípio da legalidade fiscal comporta, por outro lado, uma vertente material, de tipicidade fiscal ${ }^{4}$. Significa tal vertente que os elementos essenciais dos impostos têm de ser consagrados de forma rigorosa e definida, atento o disposto no já referido art. $^{\circ} 103 .^{\circ}$, n. $^{\circ}$ 2, da CRP.

É ainda de referir que o legislador ordinário, na LGT, concretamente no seu art. ${ }^{\circ} 8 .^{\circ}$, densificou o âmbito do princípio da legalidade tributária.

\section{As normas de impacto tributário contidas em diplomas atinentes a outros ramos do direito}

Como já referimos, a inconstitucionalidade orgânica de normas contidas em diplomas legais relativos a outros ramos do direito, concretamente o direito societário e o direito da insolvência, está na origem da litigância sobre a qual nos iremos demonstrar.

Tal circunstância decorre, aparentemente, de uma não consideração pelo legislador da interdisciplinaridade a que nos referimos supra e que conduz a que normas, prima facie de cariz não fiscal, tenham impacto nesse âmbito, impacto esse que pode ter dimensão tal que conduz ao entendimento de que estamos, em determinados casos, perante norma fiscal atentatória do princípio da reserva de lei parlamentar, como veremos de seguida.

\subsection{0 art.ำ 100. do Código da Insolvência e da Recuperação de Empresas (CIRE)}

0 processo de insolvência, enquanto processo de execução universal, tem naturalmente reflexos e impacto ao nível das dívidas de natureza fiscal, como, aliás, surge evidenciado em algumas das disposições legais de âmbito claramente tributário (cfr., v.g., o art. $^{\circ} 180 .^{\circ}$ do Código de Procedimento e de Processo Tributário - CPPT).

Um desses impactos situa-se ao nível da contagem do prazo de prescrição.

O instituto da prescrição é transversal a todas as relações creditórias, contendo, no entanto, caraterísticas muito díspares no nosso ordenamento, consoante a concreta natureza das dívidas em causa.

Naturalmente que uma disposição legal como o art. ${ }^{\circ} 100 .{ }^{\circ}$ do CIRE tem impacto ao nível das dívidas fiscais. Assim, dita a mesma que “[a] sentença de declaração da insolvência determina a suspensão de todos os prazos de prescrição (...) oponíveis pelo devedor, durante o decurso do processo".

3 Cfr. a este respeito VASQUES, Sérgio - Manual de Direito Fiscal, ob. cit., p. 284.

4 Sobre este princípio, v. DOURADO, Ana Paula - Direito Fiscal - Lições, ob. cit., pp. 144 a 158. 
Ou seja, também os prazos de prescrição de dívidas fiscais são influenciados por esta causa de suspensão.

A questão que se colocou a este propósito, nos tribunais nacionais, teve a ver com a inconstitucionalidade orgânica da norma constante do art. ${ }^{\circ} 100 .^{\circ}$ do CIRE, no que respeita à suspensão, por via da sua aplicação, dos prazos de prescrição em caso de declaração de insolvência do devedor originário de uma determinada dívida fiscal, sob duas perspetivas: a do próprio devedor originário e a do revertido.

Isto porque, atento o teor da Lei n. ${ }^{\circ}$ 39/2003, de 22 de agosto (que autorizou o Governo a legislar sobre a insolvência de pessoas singulares e coletivas), da mesma nada constava especificamente quanto a garantias dos contribuintes, tendo sido defendido que, em ambas as perspetivas assinaladas, tal feriria de inconstitucionalidade orgânica a interpretação do art. ${ }^{\circ} 100 .^{\circ}$ do CIRE no sentido de o mesmo comportar a suspensão do prazo de prescrição de dívidas de impostos.

Sobre tal questão, o Tribunal Constitucional (TC) já se pronunciou, em termos distintos, consoante estejamos perante um caso de contagem do prazo de prescrição relativamente ao devedor insolvente ou perante um caso de contagem do mencionado prazo respeitante ao revertido.

Assim, se no primeiro caso, o TC considerou não padecer o art. ${ }^{\circ} 100 .^{\circ}$ do CIRE de inconstitucionalidade orgânica, a sua decisão já foi em sentido distinto no caso da reversão (isto se não for o insolvente o próprio revertido).

Quanto aos casos em que o que estava em causa era a suspensão do prazo de prescrição relativamente a próprio devedor originário entretanto declarado insolvente, o TC pronunciou-se, designadamente, no Acórdão n. ${ }^{\circ}$ 709/2019, de 04.12.2019 (no mesmo sentido, v. os Acórdãos n. ${ }^{\circ}$ s 769/2019, de 12.12.2019, e 175/2020, de 11.03.2020).

Ali se entendeu, em síntese, que, sendo concedida ao Governo autorização para estabelecer um "processo de execução universal", nesta autorização não podem deixar de estar abrangidas todas as matérias necessárias à definição da totalidade dos créditos do insolvente, referindo-se que a suspensão da prescrição é uma "garantia de operacionalidade do processo de insolvência (...), remetendo todos os credores para o único e universal processo falimentar", aplicável à generalidade dos créditos, sob pena de se criar uma solução relativa aos créditos de natureza tributária, gerando uma desigualdade injustificada.

Já no caso de se estar perante os efeitos da declaração de insolvência do devedor originário na contagem do prazo de prescrição das dívidas relativamente ao responsável subsidiário, contra o qual houve reversão da execução fiscal, a solução não é a mesma. É pertinente a este propósito lembrar que a LGT, no n. ${ }^{\circ} 2$ do seu art. ${ }^{\circ}$ $48 .^{\circ}$, prevê que "[a]s causas de suspensão ou interrupção da prescrição aproveitam igualmente ao devedor principal e aos responsáveis solidários ou subsidiários" (sem prejuízo do disposto no . $^{\circ} 3$ do mesmo art. ${ }^{\circ} 48 .^{\circ}$ ). Ou seja, à primeira vista e atento o 
art. $^{\circ} 100 .^{\circ}$ do CIRE, suspendendo-se o prazo de prescrição relativamente ao devedor originário, tal suspensão teria reflexos na esfera jurídica do revertido.

A este propósito, no Acórdão do TC . $^{\circ}$ 557/2018, de 23.10.2018, foi declarada a inconstitucionalidade, com força obrigatória geral, da norma do art. ${ }^{\circ} 100 .^{\circ}$ do CIRE, "interpretada no sentido de que a declaração de insolvência aí prevista suspende o prazo prescricional das dívidas tributárias imputáveis ao responsável subsidiário no âmbito do processo tributário, por violação do artigo $165 .^{\circ}$, n. ${ }^{\circ}$ 1, alínea i), da Constituição da República Portuguesa”.

Neste caso, a pedra de toque reside na circunstância de não ser o revertido quem foi declarado insolvente, mas sim o devedor originário das dívidas que vieram a ser revertidas. Portanto, toda a argumentação que referimos supra não tem aqui aplicação, justamente por não estar diretamente em causa o cariz de execução universal do processo de insolvência e, como tal, não se poder considerar abrangido pela lei de autorização.

Com efeito, veja-se que o instituto da reversão já é um instituto muito particular do direito tributário, que permite que um terceiro à relação jurídico-tributária seja chamado a responder pela mesma, dada a sua especial relação em termos de condução dos destinos da devedora originária.

Neste contexto, considerou o TC, desde logo, que a prescrição das dívidas tributárias se inclui no domínio da reserva relativa de competência legislativa da AR, dado constituir uma garantia dos contribuintes. Nesse seguimento, entendeu que a Lei n. ${ }^{\circ}$ 39/2003, de 22 de agosto, não continha credencial bastante para que o Governo legislasse sobre a matéria.

O TC afastou, a este propósito, os dois argumentos esgrimidos a favor da suficiência da lei de autorização. 0 primeiro, fundado na racionalidade e na teleologia do processo de insolvência e na garantia de operacionalidade deste processo, foi afastado, por estarmos perante não o devedor insolvente, mas o responsável subsidiário que não é o insolvente e que está fora do processo de insolvência, entendendo-se que haveria uma extensão de um efeito para fora do processo de insolvência não necessária ao seu caráter universal. 0 segundo, no sentido de ser suficiente o disposto na alínea a) do n. 3 do art. ${ }^{\circ} 1 .^{\circ}$ da Lei n. ${ }^{\circ}$ 39/2003, de 22 de agosto (que legitima - Governo a legislar sobre as "consequências decorrentes do processo especial de insolvência para o Estado e a capacidade do insolvente ou seus administradores"), foi afastado, quer pela falta de especificação das consequências, quer pelo seu cariz genérico, incompatível com as exigências do art. $165 .^{\circ}$, n. ${ }^{\circ} 2$, da CRP.

Neste seguimento, como referimos, foi declarada a inconstitucionalidade orgânica, com força obrigatória geral, da norma extraída do artigo $1000^{\circ}$ do CIRE, segundo a qual a declaração de insolvência suspende o prazo de prescrição das dívidas tributárias imputáveis ao devedor subsidiário. 


\subsection{0 art- $147^{\circ}, n^{\circ}-2$, do Código das Sociedades Comerciais (CSC)}

No âmbito tributário, o art. $^{\circ} 147 .^{\circ}$ do CSC tem sido chamado à colação em situações em que houve partilha imediata dos haveres sociais de sociedade dissolvida, tendo ocorrido, ulteriormente, liquidação de tributos.

Integrado no capítulo do CSC relativo à liquidação da sociedade, 0 art. ${ }^{\circ} 147 .^{\circ}$ permite aos sócios proceder à partilha imediata, caso, à data da dissolução, a sociedade não tenha dívidas.

A esse respeito, o n. ${ }^{\circ} 2$ do mencionado art. ${ }^{\circ} 147 .^{\circ}$ prescreve que "[a]s dívidas de natureza fiscal ainda não exigíveis à data da dissolução não obstam à partilha nos termos do número anterior, mas por essas dívidas ficam ilimitada e solidariamente responsáveis todos os sócios, embora reservem, por qualquer forma, as importâncias que estimarem para o seu pagamento".

Como refere Raúl Ventura5 " "[a] existência, à data da dissolução, de dívidas de natureza fiscal ainda não exigíveis não obsta à partilha imediata (...). Em contrapartida, a responsabilidade pelas dívidas fiscais ainda não exigíveis alarga-se a todos os sócios, ilimitada e solidariamente (portanto, muito mais gravosamente do que o estabelecido no art. $163 .^{\circ}$ para o passivo superveniente)".

Nestes contextos, os sócios são chamados a responder pela dívida, enquanto responsáveis solidários.

Também aqui se tem colocado a questão da inconstitucionalidade orgânica da norma contida no n. ${ }^{\circ} 2$ do art. $^{\circ} 147 .^{\circ}$ do CSC, disposição legal esta que tem hoje a exata redação que tinha na sua origem.

O CSC, aprovado em 1986 ( $\mathrm{DL} \mathrm{n} .^{\circ}$ 262/86, de 02 de setembro), apenas teve na génese uma autorização legislativa respeitante a matéria penal (Lei n. ${ }^{\circ}$ 41/86, de 23 de setembro).

Como referimos, em termos de inconstitucionalidade orgânica do n. ${ }^{\circ} 2$ do art. $147 . .^{\circ}$ do CSC, a questão tem-se colocado em situações nas quais a liquidação de impostos ocorre já num momento ulterior ao da dissolução da sociedade e quando já tinha ocorrido a partilha, nos termos do n. ${ }^{\circ} 1$ do mesmo art. ${ }^{\circ} 147 .^{\circ}$. Nesses casos, a administração tributária tem chamado à responsabilidade os sócios.

O Tribunal Central Administrativo Sul (TCAS) pronunciou-se sobre a questão em acórdão de 22.11.2013 (Processo: 06133/12), considerando que o n. ${ }^{\circ} 2$ do art. ${ }^{\circ} 147 .^{\circ}$ do CSC não é organicamente inconstitucional, por não criar novas responsabilidades tributárias. No entanto, no mencionado aresto entendeu-se que tal norma teria de ser interpretada por forma a que a responsabilidade dos sócios não ultrapassasse o

5 VENTURA, Raúl Ventura - Dissolução e Liquidação de Sociedades. 1. ${ }^{a}$ Ed., 3. ${ }^{a}$ Reimp. Coimbra: Almedina, 2003, p. 271. 
limite estabelecido no art. $.^{\circ} 197 .^{\circ}$, n. ${ }^{\circ} 3$, do CSC, sob pena de violação dos princípios da igualdade e da proporcionalidade.

Mais tarde, já em 2019, o TCAS voltou a pronunciar-se sobre a matéria [Acórdão de 17.10.2019 (Processo: 387/18.9BELLE)], considerando não padecer o referido normativo de inconstitucionalidade orgânica, porquanto o mesmo prevê um direito que os sócios podem voluntariamente exercer (sendo, pois, possível optar pela liquidação nos termos gerais). Nesse seguimento, considerou o TCAS que não são criadas novas responsabilidades tributárias. Este acórdão foi votado por maioria, contendo um voto vencido, no sentido de se estar perante uma situação de inconstitucionalidade material (por violação dos princípios da igualdade e da proporcionalidade) e orgânica.

Pouco tempo depois, ainda em 2019, o Supremo Tribunal Administrativo (STA) pronunciou-se pela primeira vez sobre a questão, no seu Acórdão de 06.11.2019 (Processo: 0857/12.2BELRS 01173/16). Neste acórdão, que não foi igualmente votado por unanimidade, espelham-se duas perspetivas inerentes a esta questão, afastando-se do entendimento do citado Acórdão do TCAS de 22.11.2013.

A tese que obteve vencimento (seguida no Acórdão do STA de 18.11.2020 - Processo: 0879/14.9BEVIS 0377/18), partindo do entendimento de que a definição dos pressupostos da responsabilidade tributária se enquadra no âmbito da reserva relativa de lei parlamentar, designadamente por respeitar a garantias dos contribuintes, concluiu que a norma contida no art. $^{\circ} 147 .^{\circ}$, n. $^{\circ} 2$, do CSC dependia de lei formal da AR ou de DL do Governo precedido de autorização legislativa, o que não sucedeu. Como tal, desaplicou a mencionada norma, por inconstitucionalidade orgânica.

Como referimos, esta decisão não obteve unanimidade, sendo de sublinhar o entendimento diverso explanado no voto de vencido formulado (entendimento esse que, em parte, subscreve aqueloutro constante do já referido Acórdão do TCAS, de 17.10.2019 - Processo: 387/18.9BELLE).

Ali se considerou, designadamente, que o n. ${ }^{\circ} 2$ do art. ${ }^{\circ} 147 .^{\circ}$ do CSC não visou instituir uma obrigação fiscal, mas instituir um ónus que pode funcionar como instrumento de desincentivo à partilha antecipada de bens, motivo pelo qual, nesta perspetiva, não padece a norma em causa de inconstitucionalidade orgânica.

Temos, pois, duas perspetivas em confronto, sobre as quais o TC foi chamado a pronunciar-se, em sede de fiscalização sucessiva, justamente no âmbito dos autos 0857/12.2BELRS 6 .

\section{Conclusões}

Do exposto podemos concluir que a interdisciplinaridade e a cada vez mais notória interligação entre os diversos ramos do direito conduzem a que, com alguma facilidade,

6 Não tendo, à presente data (14.05.2021), sido ainda proferido acórdão. 
sejam introduzidas normas de caráter tributário em diplomas, prima facie, alheios a este ramo do direito.

Esta circunstância, atendendo ao princípio da reserva relativa de lei parlamentar que abrange os aspetos essenciais em matéria de definição quer dos carateres dos impostos quer das garantias dos contribuintes, implica que o legislador deva ter uma especial atenção e uma especial capacidade de antecipação do alcance dos efeitos de diplomas legislativos, por forma a cabalmente ser dada resposta às exigências constitucionais - designadamente sendo aprovadas as competentes autorizações legislativas.

Conclui-se dos exemplos que mostramos que, sem sombra de dúvida, não podemos considerar que existem normas estanques, sendo imprescindível encarar o ordenamento na sua complexidade e interdisciplinaridade, quer para evitar situações de eventuais inconstitucionalidades orgânicas, quer para evitar casos de dificuldade (evitável) na conciliação de regimes que, apesar de conexos, foram pensados isoladamente e, logo, de costas voltadas para as particularidades uns dos outros. 